\title{
A arte mural de Mino Cerezo Barredo no período militar brasileiro
}

\section{The mural art of Mino Cerezo Barredo in the Brazilian military period}

\section{Arte mural de Mino Cerezo Barredo en el período militar brasileño}

\author{
Márcio Luiz Fernandes*
}

\begin{abstract}
RESUMO
A denúncia política e a crítica social - desde uma leitura teológica da realidade - podem ser visualizadas nos diversos murais de Maximino Cerezo Barredo espalhados em diferentes lugares da América desde o México até a Argentina. Para Pedro Casaldáliga, bispo emérito de São Félix do Araguaia/MT, Cerezo Barredo pode ser considerado - no contexto da teologia elaborada na América Latina - como o pintor da libertação. A grandeza das obras de Cerezo expostas por todo o mundo por meio de murais, vitrais, azulejos, ilustrações em livros e revistas constituem um patrimônio que traduz de modo revolucionário como o apelo pela justiça e a luta contra os poderes opressores podem ser expressos nas imagens e refletir uma arte que provém do mundo dos pobres da América Latina. Pretende-se examinar aqui algumas obras realizadas por Cerezo no Brasil no período militar e as respectivas relações seja com o contexto da arte sacra do século XX na América Latina quanto com a denúncia dos horrores e violências praticadas contra os grupos mais vulneráveis da sociedade brasileira no referido período.

Palavras-chave: Arte mural; Cerezo Barredo; teologia e arte; pintor da libertação.
\end{abstract}

\begin{abstract}
ABASTRACT
Political denunciation and social criticism - stemming from a theological reading of reality - may be seen in the many wall paintings by Maximino Cerezo Barredo widespread through different American locations all the way from Mexico to Argentina. According to Pedro Casaldáliga, Emeritus Bishop in São Félix do Araguaia/MT, Cerezo Barredo may be considered - in the context of Latin American Theology - as the painter of Liberation. The greatness of his works - exhibited all around the world in wall paintings, stained glass, tiles, illustrations in books and magazines - constitute a patrimony that translates in a revolutionary way how the call for justice and the fight against oppressing powers may be expressed in images and reflects an art that comes from the world of poor people in Latin America. So, we examine some of his works performed in Brazil during the military period and its relationship with the twentieth century sacred art and with the denunciation of the horror and violence perpetrated against the most vulnerable groups of Brazilian society in that moment.
\end{abstract}

Keywords: Mural art; Cerezo Barredo; Theology and art; liberation painter.

\section{RESUMEN}

La denuncia política y la crítica social, a partir de una lectura teológica de la realidade, se pueden ver en los diversos murales de Maximino Cerezo Barredo, repartidos en diferentes partes de América, desde México hasta Argentina. Para Pedro Casaldáliga, obispo emérito de São Félix do Araguaia/MT, Cerezo Barredo puede considerarse, en el contexto de la teología elaborada en América Latina, como el pintor de la liberación. La grandeza de las obras de Cerezo exhibidas en todo el mundo a través de murales, vidreiras, azulejos, ilustraciones en 
libros y revistas constituyen una herencia que se traduce de una manera revolucionaria en la forma en que se puede expresar el llamado a la justicia y la lucha contra los poderes opresivos y reflejan un arte que proviene del mundo de los pobres en América Latina. Se pretende examinar aquí algunos trabajos realizados por Cerezo en Brasil en el período militar y sus respectivas relaciones tanto con el contexto del arte del siglo XX en América Latina como con la denuncia de los horrores y la violência practicada contra los grupos más vulnerables de la sociedade brasileña en el período.

Palabras claves: Arte mural; Cerezo Barredo; Teología y arte; pintor de la liberación.

\section{Introdução}

As obras murais de Cerezo Barredo espalhadas por todo o continente latino-americano permitem refletir sobre o significado de uma teologia em imagens. O patrimônio iconográfico produzido por este pintor expressa, na verdade, um modo de conceber as imagens a serviço da evangelização desde uma perspectiva decolonial. Neste caso, trata-se de realizar uma operação que se dirige a construir um novo modo de pensar e contemplar, inclusive, a figura de Cristo "numa perspectiva descolonizadora da cristologia (...) indicando que a lógica da fé cristã se manifesta no abaixamento, esvaziamento, serviço e obediência até a entrega na morte" (VASCONCELOS; HURTADO, 2016, p. 484). As imagens dos murais de Cerezo refletem a busca por uma nova linguagem. Ela é também fruto de prática teológica que procurou aproximarse da vida de fé das culturas populares. Pode-se dizer, então, que sua produção representa um projeto de reforma da tradição recebida.

O sacerdote e religioso claretiano Cerezo Barredo nasceu em 4 de agosto de 1932 na cidade de Villaviciosa, província das Astúrias, na Espanha. Já na infância sentia fortemente a vocação artística, atraído principalmente pela pintura. O seu itinerário de estudos em desenho começa na Faculdade de Belas Artes "San Carlos" em Valência e a partir de 1959 passa para a Escola de Belas Artes "San Fernando", em Madrid onde se forma. Nestes mais de cinco anos de estudo das artes e das técnicas da pintura e do desenho, Cerezo teve a oportunidade de conviver com destacados nomes da pintura e no Museu do Prado experimentou "passar horas e horas diante dos primitivistas italianos, dos mais ilustres representantes do Renascimento, diante dos pintores flamingos e, por fim, poder ver El Greco, Velásquez, Goya, Zurbarán, Ribera" (CEREZO BARREDO, 1986, p. 10).

Cerezo recebeu forte influência de seu mestre Manuel López Villaseñor (1924-1999) que se dedicou à pintura mural e cuja obra é marcada pela elaboração de uma arte de cunho social e politicamente engajada. Para perceber nitidamente esta influência basta comparar as obras de López Villaseñor - expoente da escola realista espanhola - com as obras realizadas por Cerezo na década de 60 do século passado onde se pode sentir que a 
linguagem figurativa empregada revela o grito do ser humano diante da desolante realidade sócio-política em torno.

No ano de 1970, Cerezo é enviado pelos seus superiores religiosos para os trabalhos missionários na América Latina. Durante dois anos seguidos trabalha na selva amazônica peruana, intencionado em deixar de lado a pintura e arte, pois considerava que esta atividade pudesse representar um estilo de vida burguês e distante da realidade dos mais pobres. Mas o povoado onde vivia foi devastado por um grande terremoto que destruiu as construções e, em particular, o templo católico da localidade. Cerezo passa a se responsabilizar pelo projeto da reconstrução da nova igreja e a partir dessa experiência decide pintar a luta do povo pela justiça. Este acontecimento de Junjuí foi chamado por estudiosos como a conversão artística de Cerezo (MARTINEZ, 2005; FERNANDES, 2010; FAVRE, 2012).

Assim, inspirado pelo evento do Vaticano II, pelas reflexões do episcopado em Medellin, pelo clamor do povo por justiça e pelos teólogos e mártires do continente latino-americano e caribenho Cerezo passa a compreender a sua vocação missionária e artística "descobrindo pouco a pouco aquele Jesus morto e ressuscitado que fez sua sas causas dos pobres e dos excluídos, o Jesus que outras teologias nos haviam sequestrado ou deixado em cúmplices penumbras" (CEREZO BARREDO, 2008, p. 342).

\section{A revolução espiritual em imagens}

Para Boff (2005) o surgimento da teologia da libertação representou uma revolução espiritual cuja melhor tradução pode ser contemplada nas cores, traços e beleza da arte sacra de Cerezo. Neste sentido, a produção mural de Cerezo - no seu conjunto - mantém relações com o papel exercido pela arte sacra no contexto latino-americano em suas dimensões sociais e políticas com uma proposta estética que rompe com o modelo tradicional e torna-se reflexo da opção preferencial pelos pobres. Conforme afirma Escorsi Valerio, os murais:

(...) articulam o conteúdo teológico-politico e se tornam elementos centrais para ressignificação bíblica e religiosa dos conflitos do Araguaia; promovem a identidade comunitária dos adeptos da teologia da libertação e da própria Prelazia como igreja dos pobres e contribuem para uma leitura pedagógico-evangelizadora (VALERIO, 2012, p. 182).

Se examinarmos, pois, a questão a partir do contexto da arte contemporânea, descobrimos que artistas como Cerezo, que pretendem realizar uma arte cristã, situam-se dentro de uma longa cadeia interpretativa 
que examina e atualiza os textos dos diferentes autores bíblicos e tornamse, por isso, "intérpretes de um fato inaugural que foi a revelação de Deus entre os seres humanos e que está oculto à vista" (COTTIN, 2008, p. 13). No entanto, aqui em Cerezo a função da arte aparece como um ato profético e, em estreita consonância, com a natureza revolucionária própria do cristianismo. Basta pensar aqui na figura de Jesus que com suas palavras e gestos contesta fortemente as estruturas sociais, políticas e econômicas de seu tempo. Segundo Cottin (2008) a arte cristã das origens levou em consideração esta imagem de Jesus representando-o como sofredor, pobre e humilde. Isso significa que a iconografia cristã permeada pela radicalidade do Evangelho não é fruto da teologia recente, mas tem raízes profundas na história da arte cristã.

De modo geral, não é difícil constatar o quanto as obras de Cerezo revelam um compromisso pessoal assumido com as causas latino-americanas. Tais causas são aquelas dos povos originários, dos negros, dos excluídos, enfim, do universo da vida do povo latino-americano. O processo de conversão pelo qual Cerezo pessoalmente teve de passar para poder colocar "entre parênteses" os elementos da própria cultura europeia revela seu engajamento e os esforços para valorizar os componentes da mentalidade do continente americano. Por outro lado, a decisão pelo muralismo, além de nos fazer lembrar as origens do cristianismo, nos coloca na pista da estima pelos grandes muralistas mexicanos que certamente se tornaram fonte de inspiração para uma arte militante e revolucionária. As suas obras documentam a passagem de uma visão eurocêntrica para uma dimensão pluriétnica. Esta característica humilde de realizar a epoché do pensamento e da própria tradição cultural europeia recebida é uma marca do giro decolonial. Segundo Tamayo a teologia da libertação é uma expressão do pensamento decolonial que, por sua vez, contribui para que esta teologia possa ser ajudada a reconhecer os momentos nos quais ela promoveu uma práxis decolonial e também identifica "as formas de pensamento nas quais as teologias da libertação não levaram em conta alguns aspectos da matriz colonial do poder" (TAMAYO, 2017, p. 206).

\section{Murais no período da ditadura militar}

Encontramos dois murais produzidos por Cerezo no Brasil no período militar. Neste sentido, este artista estrangeiro soma-se ao conjunto dos artistas nacionais que estavam determinados em enfrentar a situação política com os instrumentos que dispunham com sua arte, tentando despertar as consciências. Conforme evidenciara Calirman (2013) a atuação, sobretudo, 
dos artistas plásticos brasileiros sob a ditadura apresentou-se como um trabalho grupal não coeso, sem uma agenda de manifesto grupal. Pode-se documentar manifestações individuais nas quais se mantiveram práticas e discursos como forma de lutar contra o autoritarismo de Estado e diblar os orgãos de censura. No território nacional encontravam-se em várias cidades manifestações de artistas que envolviam-se ativamente para protestar contra a ditadura. Por isso, Calirman pode afirmar que nas duas décadas da ditadura militar temos um vasto e diversificado conjunto de trabalhos artísticos que indica que "nenhum individuo ativo na esfera cultural e artística do período passou incólume pelos dilemas impostos pelo regime, e cada um desenvolveu seu próprio meio de expressão em resposta" (CALIRMAN, 2013, p. 7). Já fecunda produção artística de Cerezo na América Latina, por sua vez, revela uma arte cristã elaborada comunitariamente e em oposição a todo o sistema de injustiças e perseguições praticadas pelos regimes em diversos territórios nacionais da America Latina e Caribe. Na variedade de temas abordados por Cerezo, conforme afirma Martinez (2005, p. 96) confluem “a contemplação da história dos povos à luz da fé, a ação revolucionária, a memória histórica dos pobres, o compromisso com eles, a denúncia, a forte espiritualidade radicada no Evangelho, a sacralização dos pequenos gestos".

Em sua pesquisa Helmut Renders (2013) aplica os passos oferecidos pela metodologia desenvolvida por Rose (2001) sobre as artes visuais estabelecendo três significativas modalidades para a análise das obras de arte. Esta sugestão nos parece muito apropriada para ler e interpretar a produção de Cerezo Barredo. Em primeiro lugar, será necessário acenar para a questão relacionada à modalidade tecnológica no qual o foco está em evidenciar o aspecto da circulação da obra de arte. Nasce daí perguntas que tem a ver com o âmbito no qual o artefato está colocado, se está em local privado ou público, se foi pensado como arte sacra para um particular ou para ser colocado no ambiente do templo. A modalidade tecnológica diz respeito também aos materiais utilizados para a elaboração do artefato. Em seguida, se passa à análise da modalidade composicional privilegiando os aspectos da produção da imagem em si, mostrando os traços socioculturais presentes, a linguagem corporal, as explicações históricas para as opções realizadas pelo artista, bem como o potencial e o limites representados pela obra. Por fim, chegase à modalidade social. Esta encerra os aspectos da encomenda, produção e recepção. Entram aqui aqueles que encomendaram e idealizaram a obra; o artista ou sua escola e aqueles que nela se espelharam ou com ela conviveram mostrando suas principais impressões. Obviamente, todo o propósito desta ferramenta metodológica desenvolvida por Rose (2001) visa abordar a imagem 
com a seriedade necessária que ela requer que comportam o exame integrado de pontos de vista convergentes entre si para a análise dos significados da produção de um artefato. Notamos, portanto, que, conforme fora assinalado por Renders no caso das imagens sacras, sempre será necessário observar estas três modalidades a partir de um olhar teológico. Assim, aos pontos de vista da área da produção da imagem; do campo da própria imagem em si e do horizonte do espectador devem se acrescentar um tópico referente ao programa iconográfico em perspectiva teológica.

Segundo Renders:

Quando uma cristologia passa do texto para a imagem e se torna típica para certa época e local, ela carrega em si mais uma segunda pluralidade de significados: a leitura oficial da igreja como instituição e a leitura de grupos marginalizados na igreja (e dependendo do momento histórico, marginalizados ou não na história). Quanto à interpretação de artefatos artísticos, seguimos aqui teóricos que sugerem interpretar imagens e esculturas na tripla perspectiva das modalidades tecnológicas, composicionais e sociais (2013, p. 6).

Antes de mais nada é preciso notar, na opinião de Renders, que a pluralidade de significados veiculados pelo artefato religioso exige, por sua vez, um processo de interpretação que leve a sério o fato de que a imagem envolve o espectador, em sua peculiar relação com ela. Acrescente-se o fato de que, no caso de Cerezo, suas obras foram encomendadas para serem realizadas no espaço de uma igreja. Dessa forma, todo o projeto é pensado para orientar, educar e conduzir e introduzir o fiel para ver o invisível. O fiel é convidado a olhar e tomar posição.

Iniciemos a análise do mural (Fig. 1) nos perguntando a respeito dos aspectos de produção da obra e sobre a forma da composição das imagens em suas modalidades técnicas, composicionais e sociais. Como ela foi feita e em que formato? Em São Félix a pintura é realizada sobre um muro concâvo de 8 x 3 metros, colocada na Catedral e feito com materiais encontrados no local. Faz parte do método de Cerezo a conversa e a convivência com as pessoas do local, o encontro com os materiais das culturas presentes no território. Neste particular, o uso das cores tem muito a ver com as populações indígenas e seu saber sobre o uso delas. Nos aspectos da significação das imagens temos no mural a apresentação das figuras de indios e posseiros que carregam uma cruz que vai em direção aos arames enfardados das fazendas. $\mathrm{Na}$ frente e sobre o povo está Cristo ressuscitado que guia o caminho do povo. Cristo que acompanha a luta e a esperança do povo. É um Cristo com as marcas da paixão-morte que expõe as mãos e o lado para os discípulos que o seguem. Cada uma dessas criaturas - como um sacramento - fruto 
das mãos, dos pincéis e da intuição artística de Cerezo receberá - a partir de 1977 - um nome que será dado pelo próprio bispo Dom Pedro Casaldáliga. O mural da catedral será batizado com o título: A Páscoa de Cristo e a Páscoa do Povo. Estes útimos dados nos mostram que a obra carrega uma significação teológica profunda e, por isso, seria redutivo considerar tais elementos apenas como parte do componente social da análise. Aliás, poderíamos dizer fenomenologicamente - que esta criatura é a expressão da dimensão espiritual do ser humano. Conforme afirma Edith Stein "o universo inteiro da nossa cultura bem como tudo aquilo que a mão do homem construiu, todos os utensílios, todas as obras do artesanato, da técnica e da arte são correlação do espírito que se tornou realidade" (STEIN, 1985, p. 196).

\section{Figura 1: Cerezo Barredo}

Obra Mural: A Páscoa de Cristo e a Páscoa do Povo

Catedral de São Félix do Araguaia MT - Brasil

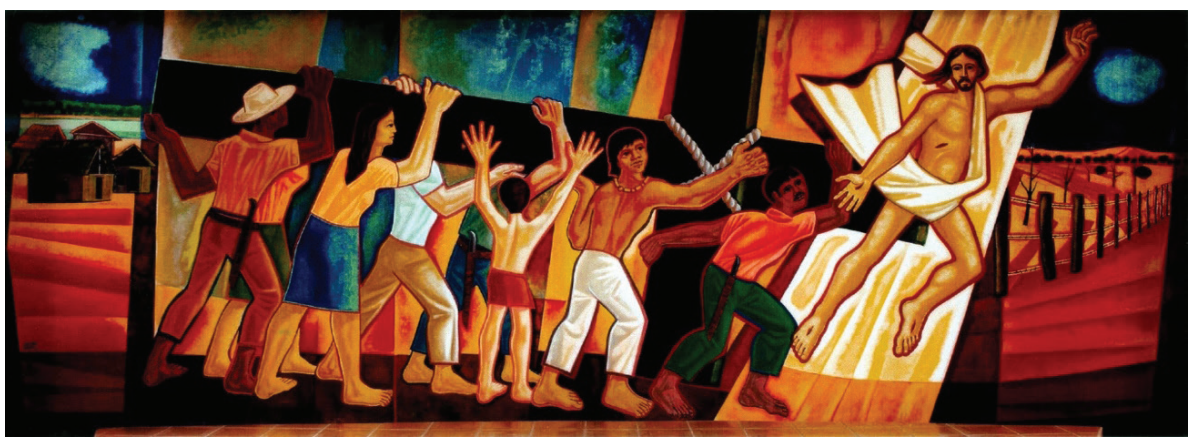

Os dados até aqui tratados sobre o mural acima introduzem o assunto a respeito dos passos que permitem realizar uma análise que leve em conta os aspectos hiléticos e noéticos que estão presentes na expressão criativa do ser humano. Vamos, então, dar mais um passo e ampliar a compreensão a respeito da modalidade social do mural explorando os aspectos da sua produção e da audiência. O escavo deve ser feito na tentativa de aprofundar as razões pelas quais o mural foi produzido, seu por quê e para quê, mas igualmente, estarmos atentos a extrair a forma como foi interpretado e recebido pela comunidade de São Félix. Em primeiro lugar, se quisermos responder ao por quê e para quê do mural, será preciso inserir a obra no horizonte de uma Igreja da Amazônia que se colocou em conflito com o latifúndio e, por conseguinte, com os poderes do Estado brasileiro que naquele momento vigiavam as ações pastorais daquela porção do povo de Deus. O mural encomendado pelo bispo a Cerezo fazia parte, portanto, de uma estratégia pastoral para entrar em comunicação mais viva com o povo 
que, no contexto brasileiro da época, era na sua maioria analfabeta. Assim, relata Pedro Casaldáliga "os murais do Cerezo faziam parte desse propósito de comunicação e pedimos para ele produzir painéis, recordando as catedrais da Idade Média, que ensinavam a catequese por meio de vitrais e pinturas" (DIAS, 2014, p. 27). Tal referência é também explicitada pelo pintor, com relação ao que o bispo pretendia do trabalho mural para que "fosse história, que fosse testemunho do cotidiano fazer caminho de sua igreja, dessa caminhada que as CEBs iam conseguindo com passos decididos na Prelazia e em toda a América Latina” (CEREZO BARREDO, 2008, p. 344).

Se aprofundarmos o componente social o mural insere-se no contexto da perseguição e das práticas pastorais de Dom Pedro Casaldaliga em São Felix do Araguaia. Sobre o ambiente do norte do Mato Grosso neste período e toda a situação sócio-politico, cultural e religiosa é muito útil a leitura da primeira Carta Pastoral de Casaldáliga de 10 de outubro de 1971 intitulada Uma Igreja da Amazônia em conflito com o latifúndio e a marginalização social que demonstra dois fundamentais elementos, a saber: a opção pelos mais vulneráveis e um pensamento pastoral iluminado pela revolução copernicana operada na Igreja Católica pelo evento do Concílio Vaticano II. Em entrevista concedida a Arcelina Helena Dias, o bispo Pedro Casaldáliga recorda:

Quando chegamos aqui, em 1968, percebemos que havia dois mundos: um dos pobres e desatendidos - índios, posseiros e peões, vivendo nas fazendas e nas casinhas e barracos dos vilarejos - e o mundo dos ricos poderosos: fazendeiros, que eram também os políticos tradicionais, contavam com o apoio da ditadura militar e viviam nas fazendas e também nas grandes capitais do Brasil. Automaticamente, você se define. Era impossível permanecer em cima do muro. Na dita normalidade, era tão clara a violência, a repressão, que você tinha que se pronunciar. Desde o início denunciamos, escrevemos. Eu digo sempre: houve dioceses ou prelazias com mais problemas que nós. Só que não se comunicavam. Passavam-se coisas terríveis nesse fundo da Amazônia, no Nordeste, no Centro-Oeste. A nossa comunicação, desde o início, era interna e externa. Tínhamos de nos comunicar com o povo, a maioria analfabeta (DIAS, 2014, p. 26-27).

Também Cerezo tem as recordações da sua intensa colaboração com Pedro Casaldáliga, desde os anos 60 do século XX, na convivência na mesma comunidade religiosa em Madrid onde ambos trabalhavam na redação da revista Iris e no envio para a América Latina:

Pedro já estava no Brasil desde 1968, doando-se com a vida, com o corpo e o coração ao povo, sentindo em sua alma as "veias abertas", sangrentas, rapaces da Grande Pátria, da Ameríndia sem fronteiras e da Igreja. E eu, depois dele em 1970, inábil aprendiz seu, de testa dura, do Peru introduzindo-me na Amazônia, tentando fazer o que podia e mais do que podia. (...) Anos duros foram aqueles para a América Latina: no Brasil, no Chile, na Argentina (CEREZO BARREDO, 2008, p. 342). 
Para elucidar aspectos da produção da obra a análise da modalidade social exige ainda esclarecimentos a respeito de como e quando o artista entra em contato com a realidade e o lugar em que realizará a sua ação criativa. O lugar sabemos que era uma Prelazia católica colocada bem no coração do Brasil que nos inicios dos anos 70 do século XX abrangia $150.000 \mathrm{~km} 2$ de extensão, dentro da Amazônia legal, no nordeste do Mato Grosso. O pintor decide - naqueles anos duros - solidarizar-se com as causas de Pedro Casaldáliga no Brasil. A descrição desta decisão podemos deixar depositada aqui com as próprias palavras do artista:

Em 1977, depois de um curso interrompido no Instituto de Pastoral do CELAM, em Medellín, afigurou-se-me como algo fora de dúvida permanecer algum tempo com Pedro em São Félix do Araguaia, solidarizar-me com sua causa em uma das etapas mais duras que esse bispo singular viveu no Brasil. E aprender um pouco mais estando com ele e seu povo, como excursus do ano sabático de Medellín. Os anos de 1976 e 1977 haviam sido particularmente terríveis para a Prelazia. Leigos e agentes de pastoral, religiosos e religiosas, sacerdotes e o próprio bispo sofriam perseguição; um igreja inteira estava sob suspeita. (...) Foi durante aquela visita fugaz de 1977 que pintei o mural da catedral de São Félix, inspirado em sua primeira e transcendental carta pastoral: Uma Igreja do Amazonas em conflito com o latifúndio e a marginalização social. Neste escrito, Pedro abordava valorosa e lucidamente o sangrento problema da terra no Brasil. Meus ouvidos e meus olhos se abriram atentos à história daquele povo, convivendo com ele e sua equipe durante aqueles dias. (CEREZO BARREDO, 2008, p. 342-43).

No aspecto da audiência em termos do componente social da obra, somos levados a nos interrogar quanto a recepção por parte daqueles que contemplam a obra. O mural da Catedral de São Félix se apresenta como uma formação material plena de sentido e, por isso, ele entra em diálogo e provoca as pessoas do lugar a voltarem sua atenção, de forma singular, para a experiência pessoal e comunitária vivida naquela situação. Para Dona Joana de Oliveira, por exemplo, os painéis suscitam a esperança pois para ela eles representam o povo: "Quando a gente olha aquele mural, fica mais alegre. Quando a gente cansa do padre falando, olha para o painel, a cruz e aquele povo carregando a cruz e a gente pensa no nossa cruz. E fica assim, assuntando...” (DIAS, 2014, p. 51). Já segundo o guia turístico da região do Araguaia - Sr. Matuzalém Pereira Milhomem Júnior (apelidado de Natural) a obra de Cerezo tem um determinado significado:

Vejo esses murais desde criança. A princípio, não me agradavam; eu sentia medo do olhar daquelas pessoas. E acho que esse é um risco para esses artistas de outros países, outras culturas. Por isso, eu preferiria que se escolhesse um artista regional. Sei que o Cerezo se esforçava, saía pelas ruas, olhando, conversando. Eu o vi, muitas vezes. 
Hoje, consigo entender e gostar mais. Além disso, sei que a proposta de nosso Bispo Casaldáliga e de Cerezo é bem diferente da do Vaticano. Lá, Jesus carrega a cruz. Aqui é o povo que carrega a Cruz, e Jesus Ressuscitado vai à frente. É mais realista essa proposta, você não acha? (DIAS, 2014, p. 37).

Para Casaldáliga a realização do processo de Evangelização passa por um envolvimento político que significa estar consciente de que o anúncio do Reino está intimamente ligado à denúncia do anti-Reino. O problema é que com muita frequência se fez a equivalência entre evangelizar com civilizar, ocidentalizar e integrar (CASALDÁLIGA, 1985, p. 73). Assim, a obra mural de Cerezo colocada na Prelazia é engajada com os conflitos e as histórias do Araguaia e está interessada em mostrar uma lógica de passagem do povo para a sua libertação. Conforme salienta um estudioso da Prelazia os murais:

(...) promovem a ressignificação religiosa e bíblica dos acontecimentos e fatos cotidianos da região do Araguaia. A inserção da realidade local e de personagens representando os diversos segmentos da população do Araguaia (como peões, posseiros, indígenas, mulheres e crianças) realiza uma integração da história, dentre motivações religiosas das pinturas. A busca por representar uma continuidade histórica do sagrado. Antes e depois, os motivos religiosos são recontextualizados na atualidade do Araguaia. O Jesus das histórias bíblicas, que outrora estava com o povo de Israel, agora conduz avante o povo de São Félix do Araguaia. Traçam a permanência da transcendência histórica e de filiar os eventos da atualidade do Araguaia diretamente aos acontecimentos bíblicos (VALERIO, 2012, p. 183).

O segundo mural de Cerezo no período militar é aquele realizado na Paróquia Nossa Senhora do Perpétuo Socorro em Taguatinga - DF no ano de 1984. Trata-se da apresentação de um grande mural com o Cristo Ressuscitado, com suas vestes brancas e com as marcas da paixão que se dirige para a assembléia com seus braços abertos. A imagem nos recorda a evangelização na Terra de Santa Cruz. Devemos lembrar que a encomenda é feita pela comunidade dos Missionários Claretianos de Taguatinga no Distrito Federal, isto é, muito perto do centro do poder em Brasilia. O Cristo é uma figura com traços mais mestiços e que a partir das paredes do presbitério quer abraçar a realidade sócio-política, cultural e religiosa do Brasil. A figura de Jesus com suas vestes brancas e de braços abertos, lembrando o símbolo da ex-capital federal do Rio de Janeiro, mostra a possibilidade da libertação das situações de morte e perseguição. Esta apresentação nos faz recordar outras imagens de Cerezo que colocadas em paralelo nos fazem perceber a intencionalidade do pintor. Basta lembrar o Cristo do Santuário dos Mártires da Caminhada em Ribeirão Cascalheira de 1986, em que no mural surge uma imagem de Jesus em primeiro plano moreno, caboclo, com vestes brancas, 
mostrando suas mãos e pés com as chagas da paixão e morte de cruz, na companhia de mártires da caminhada como padre João Bosco Burnier, Josimo, Santo Dias, Marçal e outros. Ou também podemos lembrar o mural da sala do Conselho Pastoral da diocese de Quibdó na Colômbia realizada em 1984 e, portanto, no mesmo ano deste mural de Taguatinga em que aparece um Cristo negro no centro do mural.

Figura 2: Cerezo Barredo

Obra mural na Igreja de Nossa Senhora do Perpétuo Socorro - Taguatinga DF

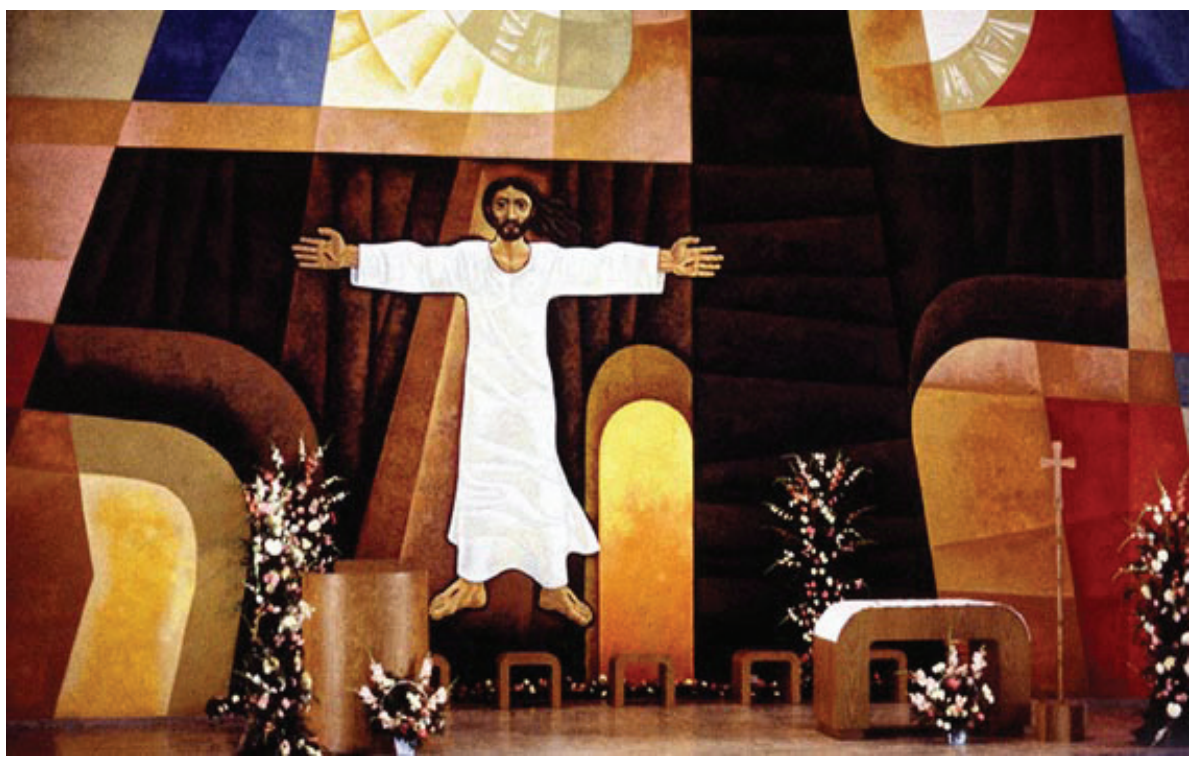

De qualquer forma, é significativo empreender uma leitura e análise dos respectivos murais de Cerezo, a partir da modalidade teológica, porque esta nos parece ser a chave hermêutica principal que se insinua no programa iconográfico presente nestas duas igrejas mencionadas acima. A arte de Cerezo é uma arte cristã e nos seus murais está um mapa para que o cristão possa fazer uma leitura critica de sua fé a partir do princípio da Encarnação do Filho de Deus. A arte proposta por Cerezo, neste sentido, é revolucionária porque no período de repressão e fechamento político da sociedade brasileira, ele traduziu o sonho de libertação nos muros de catedrais e igrejas:

Aquilo que Emmanuel Levinas dizia sobre a palavra amor posso aplicar também à palavra revolução: é uma palavra desgastada e ambígua. As palavras com o tempo assumem significados e matizes diferentes. Basta observar como alguns movimentos neoconservadores e neoliberais tem a ousadia de aparecer como revolucionários. Pois 
bem, entendo, que tudo aquilo que está em desacordo com o cruento e o necrófilo modelo de sociedade que gera a fome das massas, sem direito de viver uma vida digna e humana, maltratadas injustamente, eliminadas por razões econômicas, é potencialmente revolucionário e subversivo. Denunciar abertamente e sem ambiguidades as estratégias e não só os fatos de morte mas também o sistema que os produz é revolucionário. Ajudar a instaurar um modelo de sociedade no qual se defendam os direitos dos pobres, das etnias e das culturas massacradas e oprimidas, seu inalienável direito à propria identidade, se distribuam os bens da terra e do que geram trabalho e a técnica de forma justa, é revolucionário. Pintar aos empobrecidos, suas aspirações, seu clamor, seus passos na luta por libertação, estar ao lado deles, admitir seu protagonismo na história, crer que são os privilegiados do reino de Deus, desde agora, isto é eminentemente revolucionário. Aceitar sua cultura, crer que são portadores de uma alternativa para a construção de uma sociedade diferente, isto é revolucionário (CEREZO BARREDO, 1990, p. 4).

Cerezo nos testemunha que seus esforços para a produção de um muralismo religioso-político iniciado no período de sua estadia na Nicarágua da Revolução Sandinista foi, em muitos lugares, objeto de censura ou simplesmente de recusa do projeto. Arcelina Dias recolhe a experiência de Cerezo a respeito de uma encomenda feita para uma igreja na Argentina no período militar na qual o pintor tem de encontrar estratégias para poder transmitir sua ideia:

Minha pintura é muitas vezes forte e chocante. Fui convidado para pintar um mural na Igreja Nossa Senhora da Paz, na Argentina, e o tema proposto era a paz. Entendo que construir a paz exige também fazer memória da luta de resistência a tudo o que é contra a vida e a paz. Fiz o esboço, inclusive dos militares, e apresentei ao bispo. Ele achou muito forte e pediu para tirar os militares. Eu acabei colocando armas, de forma mais discreta, para simbolizar a luta (DIAS, 2014, p. 340).

A análise da arte sacra ou cristã de Cerezo Barredo pode ser realizada a partir do horizonte de discussões sobre as relações entre teologia e arte (CALVANI, 2010; MARIANI; VILHENA, 2011; FERNANDES, 2015; BRANCATO, 2015; RENDERS, 2013; FAVRE, 2012) e se apoiar nas modalidades de leitura ofertadas pela metodologia de Rose (2001) ou pela análise semiótica da obra pictórica em seus aspectos formais, nas dimensões denotativas e conotativas ligadas aos componentes históricos sociológicos tal como apresentado por Martinez (2005). No entanto, todos estes estudos nos fazem perceber a necessidade de perceber o componente teológico que permite a leitura global do significado presente nas obras colocadas nestas paredes, como verdadeiros lugares teológicos em vista da libertação. No quadro abaixo apresentamos uma síntese dos componentes postos em análise nas duas pinturas murais de Cerezo aqui apresentadas. 


\begin{tabular}{|c|c|c|c|}
\hline Modalidade tecnológica & \begin{tabular}{|l|} 
Modalidade \\
composicional
\end{tabular} & Modalidade social & Modalidade teológica \\
\hline $\begin{array}{l}\text { O mural está colocado de } \\
\text { forma fixa, em lugar público } \\
\text { que é a Catedral da Prelazia } \\
\text { de São Félix do Araguaia. O } \\
\text { lugar é de grande circulação } \\
\text { das pessoas pelo fato de } \\
\text { abrigar as missas, celebrações } \\
\text { que ocorrem na Prelazia. } \\
\text { Feito com material do local e } \\
\text { para fixá-lo Cerezo se serve } \\
\text { de uma cola adesiva sintética. } \\
\text { Os principais efeitos visuais se } \\
\text { dão nos formatos das mãos, } \\
\text { dos braços e dos pés, bem } \\
\text { como no uso das cores. }\end{array}$ & $\begin{array}{l}\text { Pintura feita sobre um } \\
\text { muro concavo de } 8 \times 3 \\
\text { metros que adquire este } \\
\text { formato total. } \\
\text { A relação deste mural } \\
\text { com outros textos } \\
\text { encontra-se no fato } \\
\text { de sua composição } \\
\text { revelar toda a dinâmica } \\
\text { operada na Carta } \\
\text { Pastoral intitulada: Uma } \\
\text { Igreja da Amazônia em } \\
\text { conflito com o latifúndio e a } \\
\text { marginalização social. }\end{array}$ & $\begin{array}{l}\text { Prelazia de São Félix do } \\
\text { Araguaia, Mato Groso - Brasil, } \\
\text { ano de } 1977 \text {. } \\
\text { Mural pintado quando Cerezo } \\
\text { termina a sua experiência no } \\
\text { curso de pastoral em Medellín e } \\
\text { decide solidarizar-se com as causas } \\
\text { do bispo Pedro Casaldáliga no } \\
\text { momento em que se estabelece a } \\
\text { perseguição por parte do regime } \\
\text { militar do Brasil à Prelazia de São } \\
\text { Felix e ao seu bispo Dom Pedro } \\
\text { Casaldáliga. }\end{array}$ & $\begin{array}{l}\text { Cristo aparece pintado com } \\
\text { o rosto dos pobres e entre os } \\
\text { pobres. Não está sozinho, porém } \\
\text { já não aparece entre os anjos e } \\
\text { os santos como na tradicional } \\
\text { iconografia, mas entre os peões, } \\
\text { indígenas e caboclos. Reflete-se } \\
\text { aqui a imagem eclesiológica de } \\
\text { Cristo apresentada nas decisões } \\
\text { do Episcopado Latino Americano } \\
\text { em Medellín e Puebla da opção } \\
\text { preferencial pelos pobres. } \\
\text { O mural apresenta as figuras } \\
\text { dos indios e dos posseiros que } \\
\text { carregam a cruz que se bate } \\
\text { contra as cercas de arrame } \\
\text { enfarpado de uma fazenda de um } \\
\text { dos grandes latifúndios da região. } \\
\text { Na frente deste povo e acima } \\
\text { encontra-se Jesus Ressuscitado que } \\
\text { acompanha a luta e dá esperança. }\end{array}$ \\
\hline $\begin{array}{l}\text { Mural colocado em } \\
\text { espaço público de uma } \\
\text { igreja paroquial de grande } \\
\text { circulação de fiéis. } \\
\text { O trabalho foi feito com os } \\
\text { seguintes materiais: acrílico } \\
\text { industrial sobre uma leve } \\
\text { camada de areia e cimento. } \\
\text { Os principais efeitos visuais } \\
\text { são sempre os braços de } \\
\text { Cristo, a veste branca e } \\
\text { as impressões de que ele } \\
\text { caminha na direção da } \\
\text { comunidade. }\end{array}$ & $\begin{array}{l}\text { Pintura mural feita } \\
\text { no presbitério com as } \\
\text { medidas de } 16 \times 7 \mathrm{~m} . \\
\text { Na composição não } \\
\text { aparece um estilo } \\
\text { marcadamente } \\
\text { figurativo. }\end{array}$ & $\begin{array}{l}\text { Taguatinga, Distrito Federal } \\
\text { - Brasil, ano de } \mathbf{1 9 8 4 .} \\
\text { A obra da igreja paroquial de } \\
\text { Nossa Senhora do Perpétuo } \\
\text { Socorro tem um mural central } \\
\text { na área do tabernáculo e nove } \\
\text { murais nas paredes laterais. } \\
\text { Temos aqui a representação de } \\
\text { um grande Cristo Ressuscitado } \\
\text { sobre a cruz, recordando que o } \\
\text { Brasil foi chamado de terra de } \\
\text { Santa Cruz. } \\
\text { Em } 1990 \text { nesta mesma igreja, } \\
\text { Mino será solicitado para } \\
\text { concluir a obra iniciada e realiza } \\
\text { a pintura dos sete sacramentos } \\
\text { nas paredes laterais da igreja. } \\
\text { Cada uma delas tem } 3.10 \text { x } 2.10 \\
\text { m. A obra recebe o título de: Os } \\
\text { sacramentos, dom e compromisso } \\
\text { para a construcao do Reino. O } \\
\text { tempo para a realizacao deste } \\
\text { trabalho foi de cerca de } 4 \text { meses. }\end{array}$ & $\begin{array}{l}\text { Apresenta um Cristo } \\
\text { Ressuscitado - com vestes } \\
\text { brancas - transfigurado. No } \\
\text { seu rosto temos os traços da } \\
\text { humanidade sofredora que ele } \\
\text { assumiu em sua carne e vida, por } \\
\text { isso, traz as marcas da sua paixão } \\
\text { e morte. }\end{array}$ \\
\hline
\end{tabular}




\section{Considerações finais}

Os dois murais aqui apresentados para análise só podem ser compreendidos a partir do horizonte de outras obras realizadas por vários artistas latino-americanos em memória daqueles que desapareceram, de tantos que foram aprisionados, torturados e mortos pela escolha que fizeram em lutar pela defesa do ser humano e da justiça. Deve-se lembrar que Cerezo realizou obras em toda a América Latina e neles expressou as questões próprias referentes à revolução presente na América Latina. Outro contexto que será necessário fazer memória será a repercussão profunda deixada na América Latina pelo surgimento no México, ainda na primeira metade do século $\mathrm{XX}$, do muralismo, justamente no momento em que se vivia as consequências da longa ditadura de Porfírio Diaz. Em seguida, nas primeiras décadas do século XX, com a chegada da Revolução Nacional vários artistas foram chamados para realizar e decorar edifícios públicos com grandes pinturas murais. Os mais famosos deles foram Diego Rivera, José Clemente Orozco e David Alfaro Siqueiros que souberam expressar nos muros públicos uma súplica por justiça social e representaram os níveis de degradação social e política vividos pelos povos do continente americano.

No caso da pintura da Catedral de São Felix, o mural reflete a práxis do que era e até hoje é a atividade evangelizadora daquela igreja. Aparece ali o estilo inconfundível de Cerezo que, neste mural em São Félix, na diferença com o primeiro realizado em Junjuí no Peru já manifesta sua experiência de leitura dos teólogos latino-americanos e o aprendizado realizado na convivência com Casaldáliga com quem o pintor aprendeu um olhar e sentir a partir dos crucificados da história.

Conforme afirmamos em trabalho anteriores (FERNANDES, 2015) é comum recordar o papel dos/as teólogos/as como responsáveis por difundir e desenvolver as forças renovadoras do Vaticano II e das Conferências Gerais do Episcopado Latino-Americano e Caribenho em seus notáveis documentos como de Medellín e Puebla, mas com facilidade se esquece do esforço de rejuvenescimento e atualização promovida pelos artistas cristãos. Pode-se notar fortemente nos murais de Cerezo uma forma de recepção particular de Medellin e Puebla. O patrimônio artístico inspirado pela fé cristã, no caso de Cerezo em São Félix, foi não só instrumento de anúncio do Evangelho, mas expressão de uma rica articulação entre conteúdo teológico, acão pedagógicopastoral e comprometimento político. 


\section{Referências bibliográficas}

BOFF, Leonardo. Uma revolução espiritual In: CASALDÁLIGA, Pedro.; CEREZO

BARREDO, Maximino (org.). Murais da libertação na Prelaz̧ia de São Felix do Araguaia, MT, Brasil. São Paulo: Loyola, 2005.

BRANCATO, Francesco. Teologia e arti visive: per una prospettiva antropologica. Milano: San Paolo, 2015.

CALVANI, Carlos Eduardo. Teologia da arte: espiritualidade, Igreja e cultura a partir de Paul Tillich. São Paulo: Fonte Editorial; Paulinas, 2010.

CALIRMAN, Claudia. A arte brasileira na ditadura militar. Rio de Janeiro: Reptil, 2013.

CASAldÁligA, Pedro. Com Deus no meio do povo. São Paulo: Paulinas, 1985.

CASAldÁligA, Pedro. Martírio do Pe. João Bosco Penido Burnier. São Paulo: Loyola, 2006.

CEREZO BARREDO, Maximino. Racconto autobiográfico. Pro-manuscrito: Colón, Panamá, 1986.

CEREZO BARREDO, Maximino. Yo confieso ante la crítica todopoderosa. Pro-manuscrito:

Lima, Perú, 1990.

CEREZO BARREDO, Maximino.; CASALDÁligA, Pedro. Murais da libertação na Prelaz̧ia de São Felix do Araguaia, MT, Brasil. São Paulo: Loyola, 2005.

CEREZO BARREDO, Maximino. Pedro, inspirador e guia. In: AA.VV. Pedro Casaldáliga: as causas que imprimem sentido à sua vida - Retrato de uma personalidade. São Paulo: Ave-

Maria, 2008.

COTTIN, Jerome. La mystique de l'art. Art et christianisme de 1900 à nos jours. Paris:

Éditions du Cerf, 2008.

DIAS, Arcelina Helena Públio. Memória e libertação: caminos do povo e os muráis da prelazia de São Félix do Araguaia. São Paulo: Ave-Maria, 2014.

FAVRE, Sara. Un viaggio latino-americano. Maximino Cerezo Barredo: uomo, artista, missionario. Udine: Forum, 2012.

FERNANDES, Marcio Luiz. Recepşão artística na América Latina. In: Dicionário do Concilio Vaticano II. São Paulo: Paulus, 2015, p. 797-803.

FERNANDES, Marcio Luiz. A bilética fenomenológica na obra mural latino-americana: uma mística da comunhão, in: http://www.minocerezo.it/pdf/cerezono23congressodasoter2010. pdf

MARIANI, Ceci. Baptista; VILHENA, Maria Angela (orgs.). Teologia e arte: expressões de transcendência, caminhos de renovação. São Paulo: Paulinas, 2011.

MARTINEZ, Jesus Maria. L'opera pittorica di Mino Cerezo Barredo all'interno dell'arte sacra contemporânea. Pontificia Università Salesiana, Facoltà di Scienze della Comunicazione Sociale, 2005.

RENDERS, Helmut. Cristologia iconográfica: das suas linguagens imagéticas. In: PluraRevista de Estudos de Religião, v. 4, n. 2, p. 4-31, 2013.

ROSE, Gillian. 2001. Visual methodologies: an introduction to the interpretation of visual materials. Londres: Sage Publications, 2001.

STEIN, Edith. Il problema dell'empatia. Roma: Studium, 1985. 
TAMAYO, Juan José. Teologías del sur: el giro descolonizador. Madrid: Editorial Trotta, 2017.

VALERIO, Marion Escorsi. Entre a Cruz e a Foice: Dom Pedro Casaldáliga e a significação religiosa do Araguaia. Jundiaí, SP: Paco Editorial, 2012.

VASCONCELOS, Aparecida Maria de; HURTADO, Manuel. Descolonizar a cristología. Perpectiva teológica, Belo Horizonte, v. 48, n. 3, p. 463-489, set/dez 2016.

Submetido em: 12-7-2020

Aceito em: 21-9-2020 